本层部”所組成的。

“基本层裂”，是一个以上的、沉积类型相间 妥 过同型地党运动及岩將活动影响的地层的組合。一个 構造区具有多少种㐾积类型的地层, 就相应地組成多 少个基本层缼。多少个基本层翌, 就相应地構成多少 个性質完全相異的主要構造层。凡主要構浩层数目輐 多的粠造区, 它的絬構就比較复杂, 也就是具有比較 高称的形式; 反之, 則結構比較简單, 也就是具有比 較低般的形式，簡單的結構在地孛发展央中川現較 早, 㚘其有較原始形式的基本構造單元的特色。反

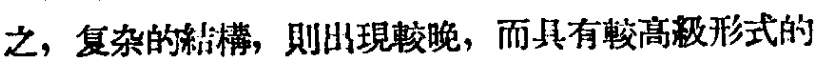
基本構造單元的标誌。

提出这个新标准的事实根据是: 第一, 不同性锤

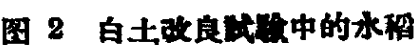

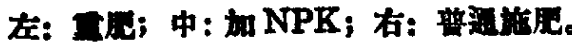

每 100 克土㙳中 18 毫克当量以上。由 于白土分布的

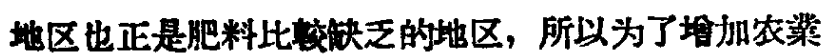

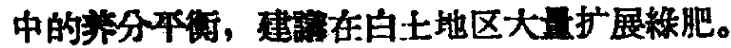

・中国科学院土㳟研究所白土工作組

\section{划分大地檄造区的一項新 标准一結椾}

通常划分權造区域，多着重于地层、構造变动、 岩策作用及地䅨等方面的特点，而对一个地区的发展 过程的分析及其阶段的划分，注意不能，以致有时使 一些地区的大地棒造性留問題，久量末决，从而阻碍 了我们对于新基本棬造單元的发現和認識。

划分搼透区域的有效方法是历史分析法。这是唯 物棓证法在大地構浩学上的具体运月。我們必須对一 个地区的同一发展阶段出現的各方面特点加以全面考 点, 而不可抓住其中的基一方面的特点，把它孤立起 来, 作为标准。其次, 必須把一个地区的不同发嫏阶 段的特点联系起来，而不可抓住㷊一阶段的片段事 笑，制断开来，作为根据，第三，必須把一个地区的 地贾发展史中不同时期的特点，依其出現順序，依次 排列，据此划分阶段。因为不同发展阶段反咉了事 物的资的变化。

为使划分大地粠造区时能够正确地反映一个地区

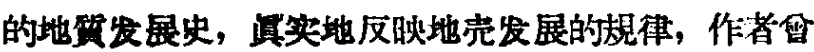
根据笑践經驗，在运用历史分析法时，增问一項新标 谁。这就是“結楼”。

这里所称的“結椿”，是指一个構造区具有多少个 “主要粠造展”。这些主要橉造层是由各自特有的“基 的基本構造單元是互相区別而又互相联系的。它倨之 間具有不同复杂程度的发展史，四而造成不闰数目、 不同性䝷的基本层覃，抹的此構成相应的主要構造

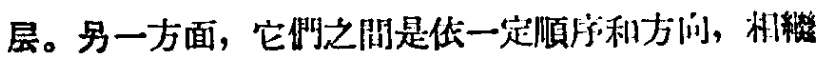
轉化，順次更替的; 一个構适区，在其发统过程中仿 多称历一次轉化，即多形成一个主要棌造层。[N此， 一个棒造区具有的主要構造层数目多少，随言它所烧

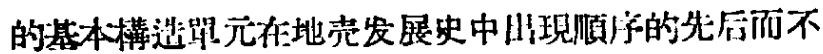
同: 凡H現較等的基本構造單元，其主要槛选层較

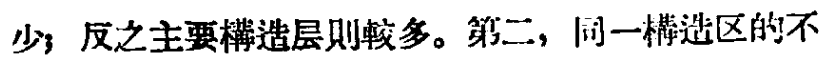
同发展阶段，也是互机区别而文互、相联系的。它体现

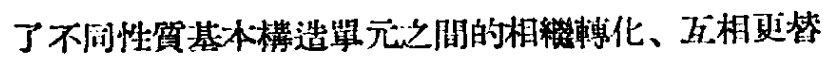

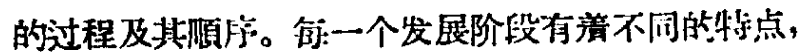
但每一阶段都克服了它的湔一阶段的形式，抹楼承了 它的茮些基本內产，作为自己的組成部分，同时加入 了自己特有的、新的縕成部分和牪点, 循着上利的路 䋐发展轉变而成的。

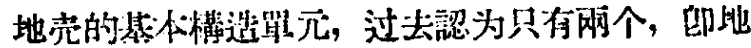

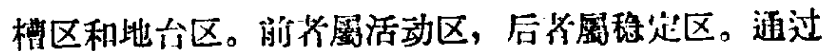
地台活化的研労，我制已經发現，它們实际上不止二: 个而是多个，就已䘞者耐論，除地槽区及地台区外， 还有一个“躬三基本蒂造單元”，印的地台区重新活动 轉化而成的“地经区”和。其中地槽区是这些已知基本

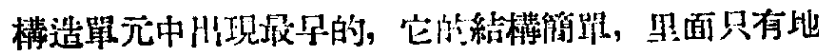

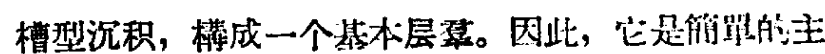
要構造层，屬于低級形式的結满。山地槽区䡔化而成

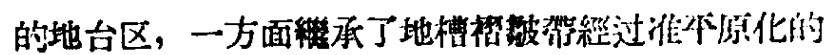

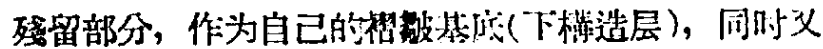

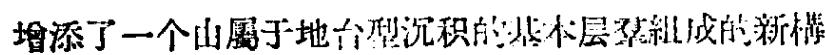
造层一“沉积盖层”(上棈造层)。所以，它足双层絬

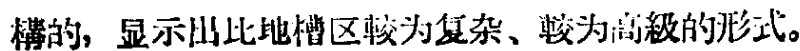


由地台区轉化而成的地翟区，則秋承了地台区的下、 上兩个構造层, 作为自己的第一、二構造层, 同时义

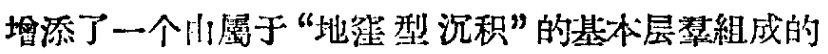

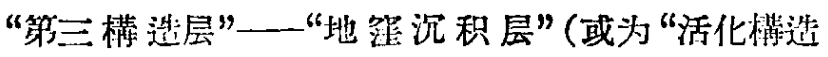
层”。所以, 它具有三个主要構造层, 是現知的三个 基本構造單元中結構最为复杂、形式最为消級的一 种。

你作者的見解, 在运领經过引伸和发展的历史分 析法来划分檏造区域的时候，应該注意收集八个方面

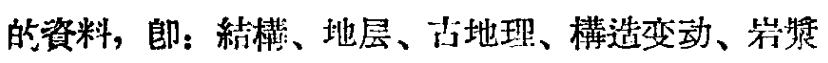

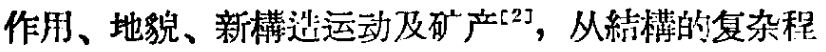

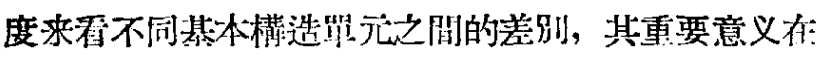

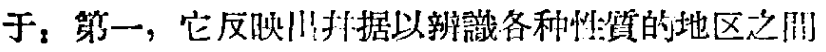
的贸的差别、轉化关系和在地売发 展史中的出現顺 序, 从而正确地制別它們是屬于们种基本構造單元。 第二, 它使我們認識一个地区的地質发展过程的复杂 程度以及不同阶段的特点, 从而推知該地区的成矿作 用发展史，有助于找川矿产分有的規伊。但必須指 出, 把这个方面的特点作为鑑別一个地区大地構造性: 筫的标准之一，㚘不是与其他方面的标准割!裂开来。 相反地, 它綜合了其他几个主要方面的特点, 扭按照 发展阶段的先后, 重憼川一个地区的地質发展史, 从 而正确地得州关于大地㮖造性質問題的結論。

\section{陈国达}

(中南矿冶学院地筫探矿系) 1959 年 1 月 15 日

[1] 陈国达: 地管的第三基本構造單元一一地萑区，科 学通报, 1959年第 3 期。

[2] 陈国达：地台活化訊及其找矿意义，地賢出版社。

\section{矿物中鈰的存在狀态}

根据过去研究的給果, 鈰在矿物中大多成三价的 鼎态而存在。虽然在葉些矿物中(邚銈鈰矿)发现有川

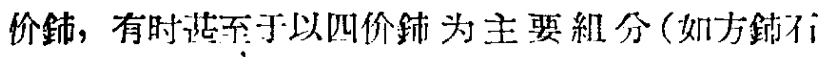
cerianite) 但象这样的矿物为数是不多的。

在研究我国产的易解不和新发现的震日百的“时, 测

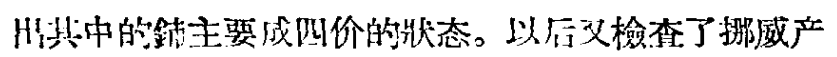
的一种易解不i，同样发現有四价鈰存在。因而使我們 想到, 矿物中四价銱的存在可能是比較普遥的, 扑不 象过去所了解的那样少。

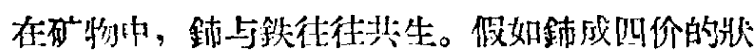
态与亞鉄闹时你在于矿物中时, 过立是沟有办法来测 它它們的含量的。因为当硅物以酸塎解时, 垖发生氧
化还原反应, $\mathrm{Fe}^{2+}$ 氧化为 $\mathrm{Fe}^{8+}$, 而 $\mathrm{Ce}^{4+}$ 还原为 $\mathrm{Ce}^{8+}$ 。 假如亞鉄的含量低，而四价鈰的含量高时，可以测H 部分的四价鈰。但在这种情况下，所测出的 $\mathrm{CeO}_{2}$ 及 $\mathrm{Fe}_{2} \mathrm{O}_{3}$ 都是鍇誤的。在过去的分析結果中，估訫这和

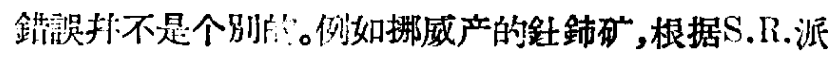
㡹尔研究的結果，其中 $\mathrm{CeO}_{2}$ 的含量为 $5.48 \%$, $\mathrm{Ce}_{2} \mathrm{O}_{3}$ 的会量 为 $6.13 \%, \mathrm{Fe}_{2} \mathrm{O}_{3}$ 的会量为 $4.25 \%$ 。 这很可能就是在艘分解矿样的过程中, 部分的 $\mathrm{Ce}^{4+}$ 氧化矿样中的 $\mathrm{Fe}^{2+}$ ，团而使 $\mathrm{Ce}_{2} \mathrm{O}$ 的测定值侻低，而 使 $\mathrm{Fe}_{2} \mathrm{O}_{3}$ 和 $\mathrm{Ce}_{2} \mathrm{O}_{3}$ 的测定值 偏高, $\mathrm{FeO}$ 则末筧测 H!。

为了正确地研究鈰在自然界中的存在妝态和矿物

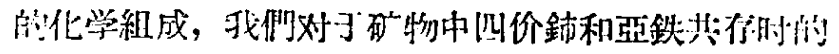
测定問题, 进行了研究, 打获得了初步的成果。现住: 总絬为以下儿点, 以供进一步研究时的㰦考:

(1) 应用磷酸塎矿法可以测定矿物中的红价鈰。 但磷酸的純度必須严的注意, 假如磷酸中才保有还原 剂时, 就不能使川。

（2）应用磷酸一一五氧化二钢法，以高銛酸叙标

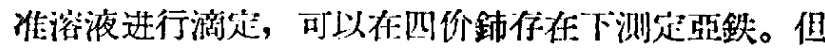
五氧化二钢的湦度不宜太大，一般以足够氧化矿样中 的亞鉄拌秒秒过量为宜。否则对谪定終点的覌察有所 不便。

（3）矿物中四价鋪的定性有以下几个方法:(i) 磷 酸溶解矿物以后，在稀釋过的溶液中，扣入 $1-2$ 滴

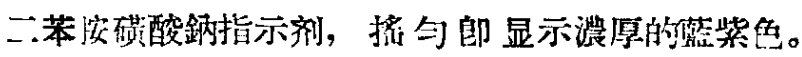

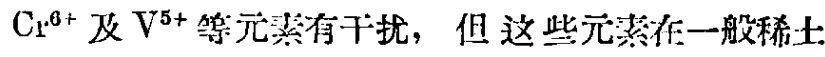
类元素矿物中都不存在。(ii) 当肞磷酸一五氧化二。

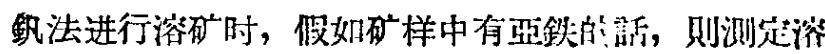
液將叫現四价釷的螕色。而当稀釋以后，以硫酸亞鉄 銨标准溶液进行滴定多余的五价釷时，在有四价鈰存 在法情况下，將发現所洕耗的。硫酸亞鉄銨标准液的

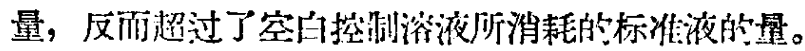

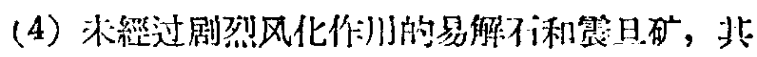

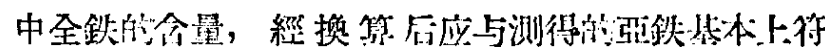

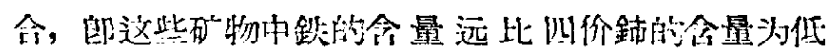

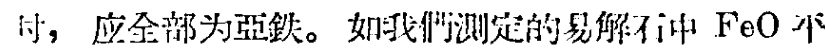

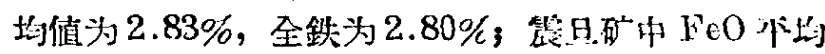
值为 $1.36 \%$ ，全鉄为 $1.61 \%$ 。經过剧烈的风化作用 的例外。如另一块謷旦矿标体中测得的丝鉄为 $0.61 \%$, 而全鉄为 $2.38 \%$, 直 接测定的 $\mathrm{CeO}_{2}$ 为 $6.34 \%$, 矿 物中应有 $\mathrm{CeO}_{2}$ 为 $7.83 \%$ ，这是由于亞鉄敒风化㳡程 中容易氧化所致。

（5）易解石与震旦矿中可能无三价鋪存作。其理 